\title{
All Are Aromatic: A 3D Globally Aromatic Cage Containing Five Types of
}

\section{D Aromatic Macrocycles}

Longbin Ren ${ }^{1}$, Yi Han ${ }^{1}$, Xudong $\mathrm{Hou}^{1}$, Yong $\mathrm{Ni}^{1}$ and Jishan $\mathrm{Wu}^{1,2 *}$

${ }^{1}$ Department of Chemistry, National University of Singapore, 3 Science Drive 3, 117543, Singapore

${ }^{2}$ Joint School of National University of Singapore and Tianjin University, International Campus of Tianjin University, Binhai New City, Fuzhou 350207, China

E-mail: chmwuj@nus.edu.sg

Graphical abstract:

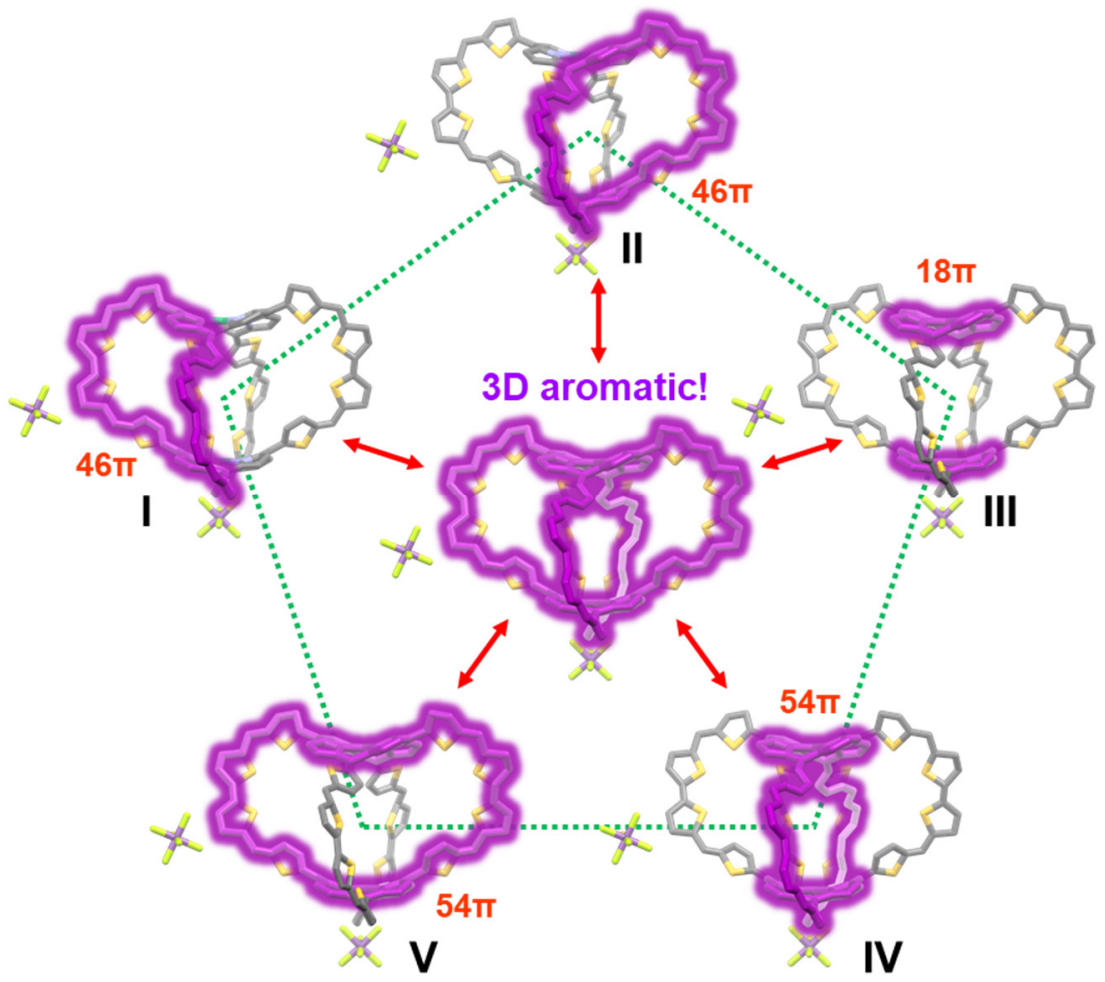

The studies on three-dimensional (3D) aromaticity have been mainly focused on fullerenes, boronbased deltahedrons/clusters, metal clusters and polyhedral hydrocarbons, but there are very limited researches on the fundamental aromaticity rule for 3D fully $\pi$-conjugated molecules. Herein, we report a $\pi$-conjugated molecular cage in which two aromatic porphyrin units are bridged by four thiophenebased arms. Two-electron chemical oxidation leads to a 3D globally aromatic cage with a $C_{2}$ symmetry according to X-ray diffraction, NMR, electronic absorption spectra, and theoretical calculations. 

of two-dimensional (2D) macrocycles in the cage skeleton are aromatic and follow Hückel rule. The switch from localized aromaticity to global aromaticity upon chemical oxidation is also observed in a tricyclic model compound. The study indicates that to attain 3D global aromaticity in a molecular cage, all the formally available $\pi$-conjugated macrocycles should be $2 \mathrm{D}$ aromatic.

Aromaticity is initially confined to planar two-dimensional (2D) $\pi$-conjugated monocyclic molecules, which follow [4N+2] Hückle rule. ${ }^{1-5}$ Over the years, studies have demonstrated that this concept is also applicable for diverse structures in which $\pi$ - and/or $\sigma$ - electrons can be efficiently delocalized and result in stabilization. For example, 2D $\pi$-conjugated polycyclic molecules could be globally aromatic if there is a dominant [n]annulene-like $(n=4 \mathrm{~N}+2)$ ring current circuit, as observed in porphyrinoids, ${ }^{6-8}$ porphyrin-based nanorings, ${ }^{9-10}$ and non-benzenoid polycyclic hydrocarbons. ${ }^{11-12}$ On the other hand, Möbius twists ${ }^{13-20}$ and triplet $[\mathrm{n}]$ annulenes ${ }^{21-25}$ follow a $[4 \mathrm{~N}]$ aromaticity rule. The recognition of three-dimensional (3D) aromaticity can be dated back 60 years ago when Lipscomb et al considered $\left[\mathrm{B}_{12} \mathrm{H}_{12}\right]^{2-}$ as a superaromatic molecule. ${ }^{26}$ Later studies showed that closo boron hydrides $\left[\mathrm{B}_{n} \mathrm{H}_{n}\right]^{2-}(6 \leq n \leq 12)^{27-28}$ and some boron-based clusters $^{29-31}$ are also aromatic. A correlation between classic 2D polycyclic aromatic hydrocarbons and these deltahedral boron hydrides was established by Poater et al by showing that both share a common origin regulated by the valence electrons in confined space. ${ }^{32}$ In 2002 , Hirsch et al presented a $2(\mathrm{~N}+1)^{2}$ spherical aromaticity rule for $I_{\mathrm{h}}$ symmetric fullerenes after considering the similarities of the their molecular orbitals with radial-symmetric atomic orbitals. ${ }^{33-35}$ This rule was also found applicable for some highly symmetric polyhedral hydrocarbons ${ }^{36-37}$ and metal clusters. ${ }^{38-40}$ It was further theoretically extended to open-shell systems by Solà et $a l .{ }^{41}$ In addition, close stacking between antiaromatic molecules could lead to enhanced aromaticity. ${ }^{42-44}$ All these studies demonstrate that $\pi$-/ $\sigma$-conjugated molecules or clusters always have the tendency to reach the lowest-energy state (aromatic) through electron delocalization. 
Surprisingly, the investigated 3D aromatic systems cover very little about the fully $\pi$-conjugated molecular cages or polyhedrons, although $2 \mathrm{D} \pi$-aromaticity was widely studied. This is probably because the synthesis of $3 \mathrm{D} \pi$-conjugated systems with all $\pi$-electrons being fully delocalized along the $3 \mathrm{D}$ skeleton is a very challenging task. There were indeed a number of $3 \mathrm{D} \pi$-conjugated molecular cages, ${ }^{45-52}$ but the $\pi$ electrons are mainly localized in individual benzenoid rings, or only delocalized along one or two macrocycles, not fully delocalized at three dimensions. Our group recently demonstrated that a three-fold symmetric diradicaloid molecular cage showed 3D global aromaticity at the hexacationic state $\left(c-\mathbf{T}_{\mathbf{1 2}}{ }^{\mathbf{6}}\right)$, and a $[6 \mathrm{~N}+2]$ electron counting rule was proposed for this specific type of $D_{3}$ symmetric molecular cage. ${ }^{53}$ The study also implied that this pseudo-spherical symmetric cage containing 50 delocalized $\pi$-electrons could also satisfy Hirsch's $2(\mathrm{~N}+1)^{2}$ rule $(N=4)$ in analogue to fullerene $\mathrm{C}_{60}{ }^{10+}$. However, the much lower symmetry ( $D_{3}$ symmetry) in comparison to the ideal $I_{\mathrm{h}}$ symmetry for $\mathrm{C}_{60}{ }^{10+}$ deferred a clear conclusion. So, whether the 3D fully electron-delocalized molecular cage follows the 2D Hückel rule for each individual macrocycle or a $3 \mathrm{D}$ Hirsch $2(\mathrm{~N}+1)^{2}$ rule remains a question. To deeper understand the $3 \mathrm{D}$ global $\pi$-aromaticity, it is necessary to synthesize more complex molecular cages with higher symmetry. In this context, we designed a four-fold symmetric molecular cage $\mathbf{1}$ in which two aromatic porphyrin units are linked by four thiophenebased linkers (Scheme 1). The porphyrin and thiophene rings are chosen because they allow 3D electron delocalization as compared to the aromatic benzene ring-based molecules. ${ }^{6-10,53}$ While the neutral cage compound may still possess 2D localized aromaticity of the porphyrin unit, it could be converted into a 3D globally aromatic cage upon chemical oxidation. Indeed, our studies reveal that its dication $\left(\mathbf{1}^{\mathbf{2}}\right)$ show a desired 3D global aromaticity. More importantly, we found that all the individual 2D macrocycles formed by the four arms and the fragments of the porphyrin unit, including the two porphyrin macrocycles, are aromatic and follow Hückel's [4N+2] aromaticity rule. This indicate a close correlation between 3D global 
aromaticity and 2D Hückel aromaticity. In this Article, we report the detailed synthesis, physical characterization, and analysis on the 3D aromaticity.

A

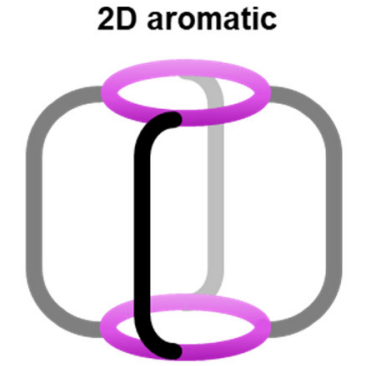

3D aromatic

Ox.

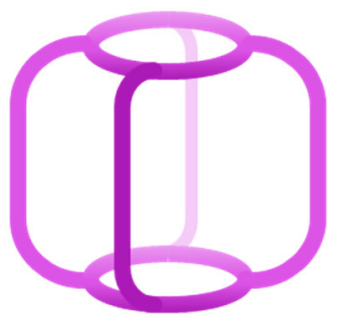

B
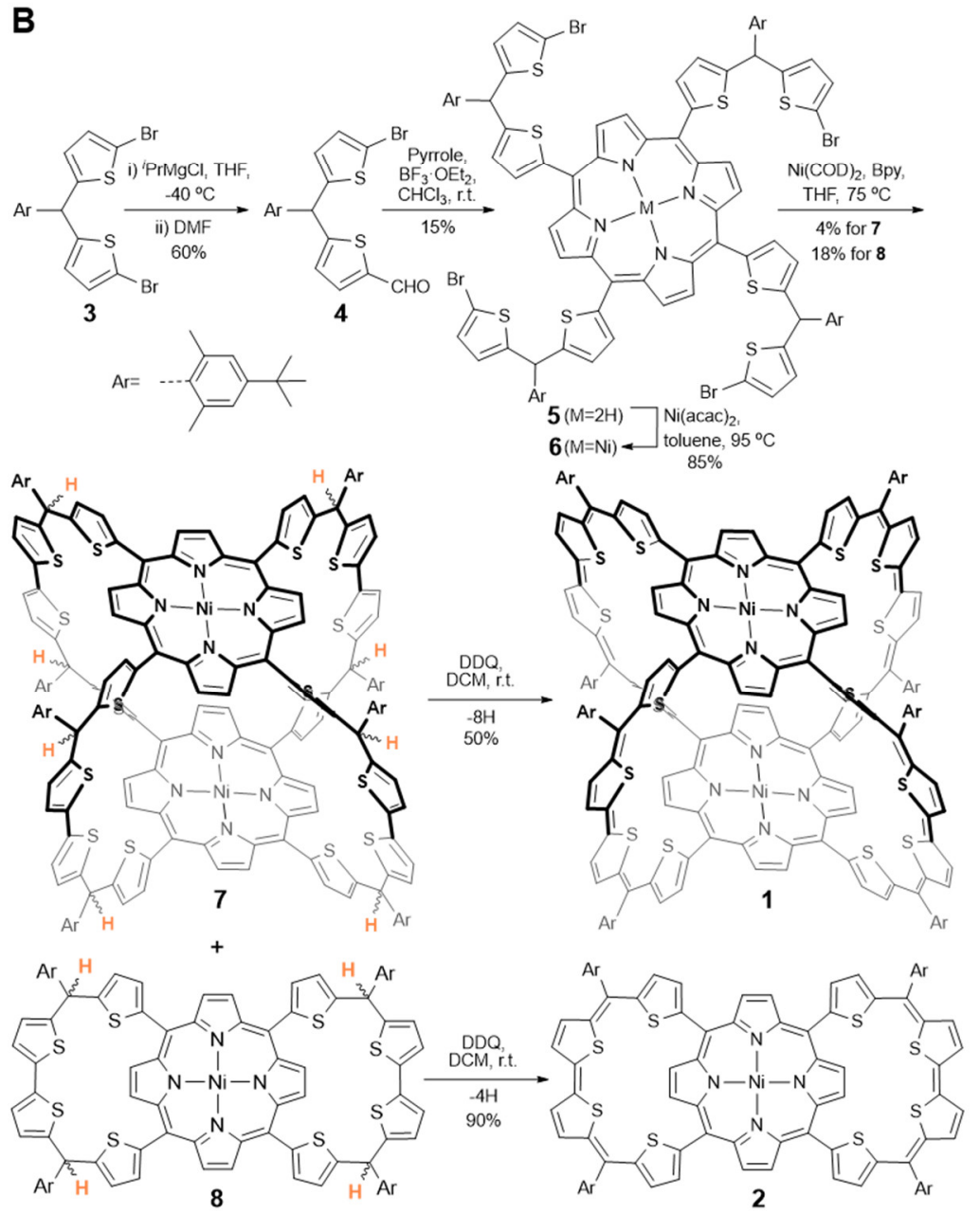

Scheme 1. Design and synthesis of a 3D $\pi$-conjugated molecular cage 1 . (A) The design of a $\pi$-conjugated molecular cage containing two aromatic porphyrin units (the rings highlighted in purple color) and four thiophene-based arms (the arcs in black/grey color). It can be converted into a 3D global aromatic cage (right side with all in purple color) upon chemical oxidation (Ox.). (B) Synthesis of the cage 1 through intermolecular Yamamoto coupling reaction of the intermediate 6 followed by oxidative dehydrogenation reaction. The intramolecular coupling product $\mathbf{8}$ was also isolated and subsequent dehydrogenation gave the corresponding $\pi$-conjugated tricyclic compound 2. Bpy: 2,2'-bipyridyl; COD: 1,5-cyclooctadiene; r.t.: room temperature. 


\section{Results and discussion}

The molecular cage was synthesized by $\mathrm{Ni}(\mathrm{COD})_{2}$-mediated intermolecular Yamamoto coupling of the intermediate compound 6 followed by oxidative dehydrogenation of the isolated octahydro- cage 7 by 2,3-dichloro-5,6-dicyano-1,4-benzoquinone (DDQ) in dichloromethane (DCM) (Scheme 1). The key intermediate $\mathbf{6}$ was prepared by a reaction sequence involving formylation, Alder-Longo condensation and nickel (II) ion insertion starting from 3. During the Yamamoto coupling reaction, an intramolecularly coupled tricyclic product $\mathbf{8}$ was also obtained, and subsequent oxidative dehydrogenation gave the fully conjugated macrocycle $\mathbf{2}$, which can serve as a model compound to understand the switch from localized aromaticity to global aromaticity upon chemical oxidation. In both molecules, bulky 4-tert-butyl-2,6-dimethylphenyl groups are attached onto the most reactive methylene sites. Thus, the final products are soluble and stable and can be purified by routine silica gel column chromatography.

The cyclic voltammogram and differential pulse voltammogram of $\mathbf{1}$ shows three reversible oxidation waves with half-wave potential $\left(E_{1 / 2}{ }^{\mathrm{ox}}\right)$ at $0.01,0.41,1.02 \mathrm{~V}$ and three reversible reduction waves with halfwave potential $\left(E_{1 / 2}{ }^{\text {red }}\right)$ at $-1.40,-1.67,-1.86 \mathrm{~V}\left(\mathrm{vs} \mathrm{Fc}^{+} / \mathrm{Fc}, \mathrm{Fc}\right.$ : ferrocene) (Figure 1A). Compound 2 also exhibits amphoteric redox behaviour, with four reversible oxidation waves $\left(E_{1 / 2}{ }^{\mathrm{ox}}\right.$ at $-0.09,0.01,0.28,0.45$ $\mathrm{V})$ and one reversible reduction wave $\left(E_{1 / 2}{ }^{\text {red }}\right.$ at $\left.-1.44 \mathrm{~V}\right)$ (Figure 1B). Tw-electron chemical oxidation of both $\mathbf{1}$ and $\mathbf{2}$ by oxidant $\mathrm{NO} \cdot \mathrm{SbF}_{6}$ gave the corresponding dication $\mathbf{1}^{\mathbf{2}}$ and $\mathbf{2}^{\mathbf{2}}$ (see evolution of electronic absorption spectra during the chemical titration: Supplementary Information Fig. S1 and Fig. S2), which could be isolated in single-crystal form. No higher oxidation state species could be obtained even when excessive oxidant was added. Compound 1 in DCM shows an intense Soret band with maximum ( $\left.\lambda_{\mathrm{abs}}\right)$ at 425 $\mathrm{nm}$ which is typical for porphyrin, and another intense band with $\lambda_{\mathrm{abs}}$ at $545 \mathrm{~nm}$ which is reminiscent of that for quinoidal bithiophene moieties (Figure 1C), indicating that the porphyrin units and the four arms are not well conjugated. On the other hand, its dication displays a broad absorption band at near-infrared (NIR) 
region extending beyond $1600 \mathrm{~nm}$, indicating effective $\pi$-electron delocalization. The existence of an intense band with $\lambda_{\text {abs }}$ at $683 \mathrm{~nm}$ also implies a possible global aromatic character. Compound 2 shows similar absorption band to $\mathbf{1}$ with the lowest-energy band split, presumably due to its more rigid structure (Figure 1D). However, its dication exhibits an intense band even at the NIR region $\left(\lambda_{\text {abs }}=1068 \mathrm{~nm}\right)$.
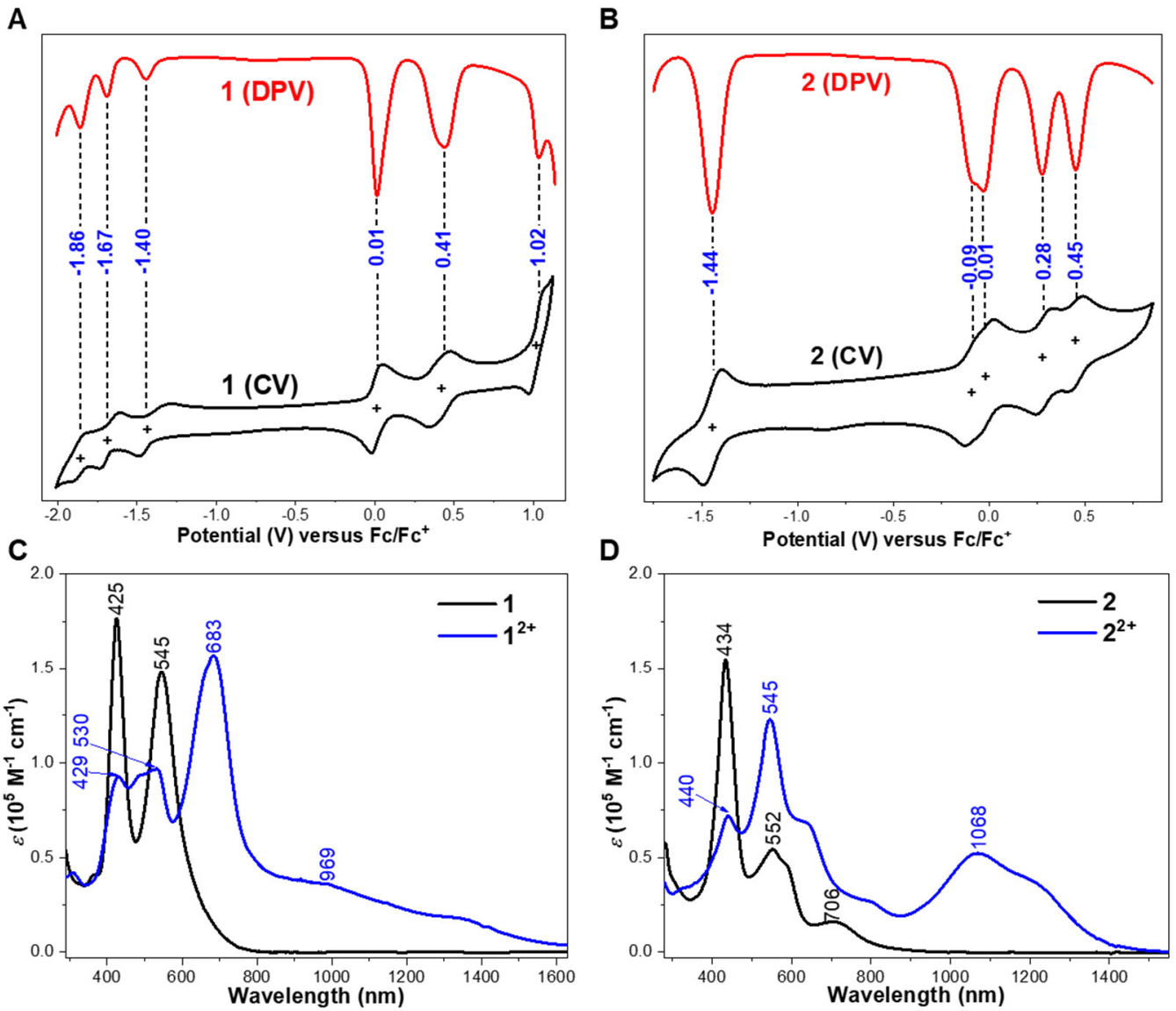

Figure 1. Electrochemical and optical properties. Cyclic voltammograms (CV, black line) and differential pulse voltammograms (DPV, red line) of 1 (A) and 2 (B) in $\mathrm{DCM}$ (with $0.1 \mathrm{M} \mathrm{Bu} 4 \mathrm{~N} \cdot \mathrm{PF}_{6}$ as supporting electrolyte). Electronic absorption spectra of 1 (C) and 2 (D) and their dications in DCM.

X-ray crystallographic analysis of the single crystal of 1 at $100 \mathrm{~K}$ reveals a slant cage structure with a center of symmetry (Figure 2A). The two porphyrin rings remain nearly planar and aligned parallel to each other, with a plane-to-plane distance of about $7.8 \AA$. The sulfur atoms of the middle bithiophene units point inside the cavity with the distance between the opposite sulfur atoms being $16.95 \AA / 17.43 \AA$, which could represent the inner diameter of $\mathbf{1}$. The distortional angles between the porphyrins and the neighbouring thiophene units are about $58.8^{\circ}, 62.3^{\circ}, 77.5^{\circ}$ and $89.2^{\circ}$, implying a weak $\pi$-conjugation between them. This 
is further evident from its ${ }^{1} \mathrm{H}$ NMR spectrum in $\mathrm{CDCl}_{3}$ at $298 \mathrm{~K}$ (Figure 3A). The resonance for the $\beta$ - $\mathrm{H}$ (proton $e$ ) of the porphyrin unit appears at the chemical shift $\delta=8.83 \mathrm{ppm}$, typical for aromatic porphyrin. The resonances for the bithiophene units (protons $a$ and $b$ ) appear as doublet at $\delta=7.00 \mathrm{ppm}$ and $6.33 \mathrm{ppm}$, respectively, indicating a dominant quinoidal structure. The resonances for the protons $c$ and $d$ on the thiophene rings that directly linked to the porphyrin unit are broadened and split, with $\delta$ at about 6.54 and $7.02 \mathrm{ppm}$, which can be explained by the slow dynamic rotation of the thiophene ring as previously observed in another analogous 2D system. ${ }^{54}$ Accordingly, the peak for the proton $e$ is also broadened and split, but heating the solution of $\mathbf{1}$ in $\mathrm{CDCl}_{2} \mathrm{CDCl}_{2}$ from $298 \mathrm{~K}$ to $393 \mathrm{~K}$ (Supplementary Information Fig. S3 and Fig. S4) did not result in sharpening of the resonances, indicating a substantially high rotation energy barrier.

A

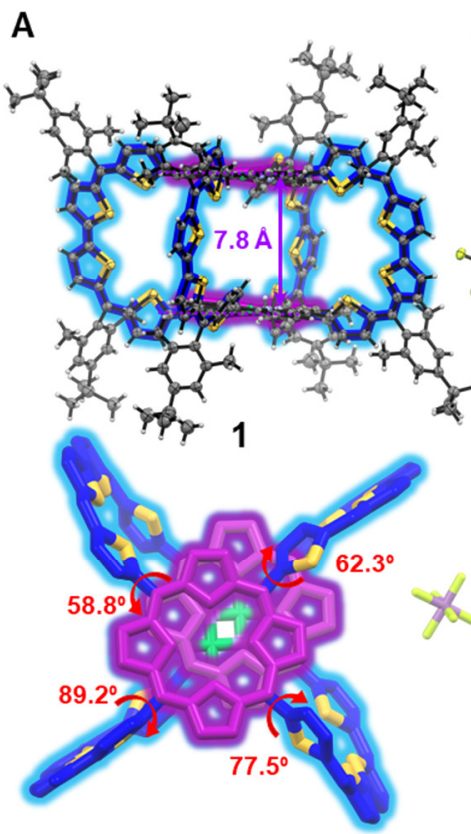

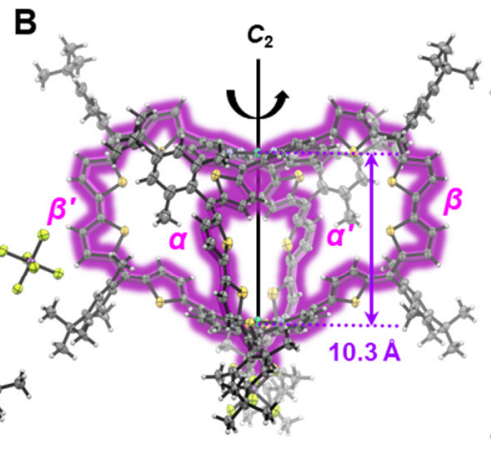
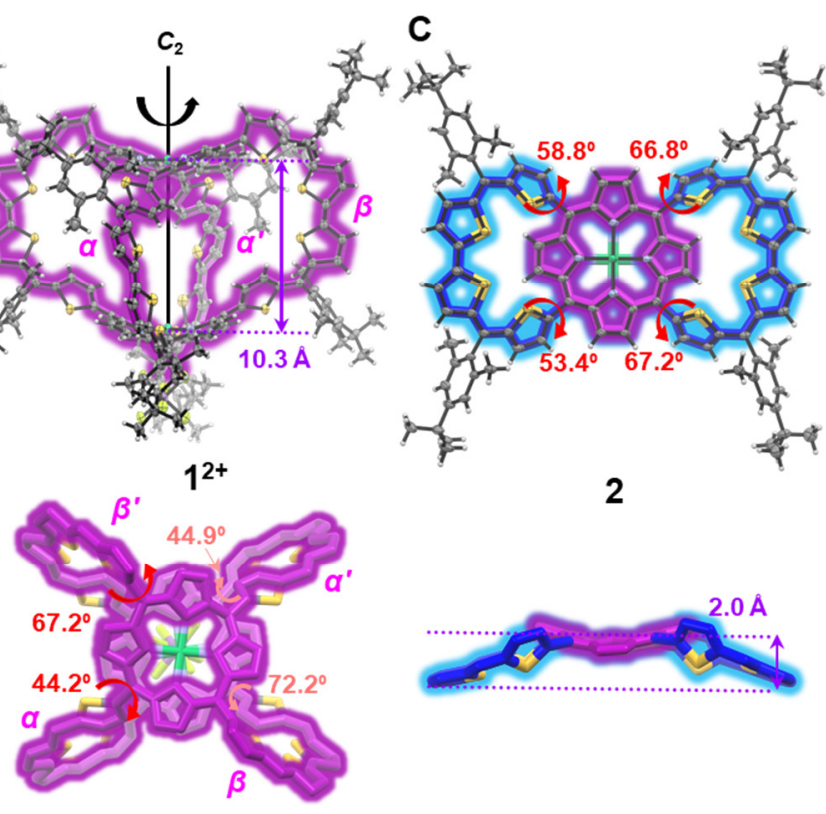

2

D

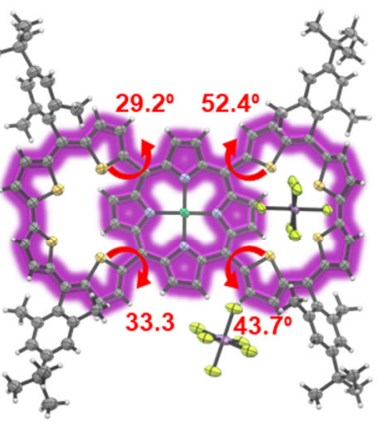

$2^{2+}$
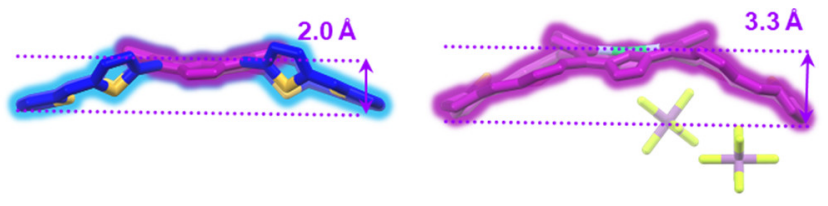

Figure 2. X-ray crystallographic structures. (A) 1 , (B) $\mathbf{1}^{2+}$, (C) 2 and (D) $\mathbf{2}^{2+}$. Top row: the side views of $\mathbf{1}$ and $\mathbf{1}^{2+}$ and top views of $\mathbf{2}$ and $\mathbf{2}^{\mathbf{2 +}}$ presented by ORTEP diagram at $8 \%, 8 \%, 30 \%, 20 \%$ probability, respectively. Bottom row: the top views of $\mathbf{1}$ and $\mathbf{1}^{\mathbf{2 +}}$ and side views of $\mathbf{2}$ and $\mathbf{2}^{\mathbf{2 +}}$ with only the $\pi$-conjugated backbones being displayed. The $C_{2}$ rotational axis in $\mathbf{1}^{2+}$ is drawn. The red arrows and numbers show the distortional angles between the porphyrin and the neighboring thiophene rings, and the blue double-headed arrows and numbers represent the distances between the two planes or the depth of the cavities. The main $\pi$ conjugation pathways for the global aromatic units are highlighted in purple color while the electronlocalized linkages are highlighted in blue color. 


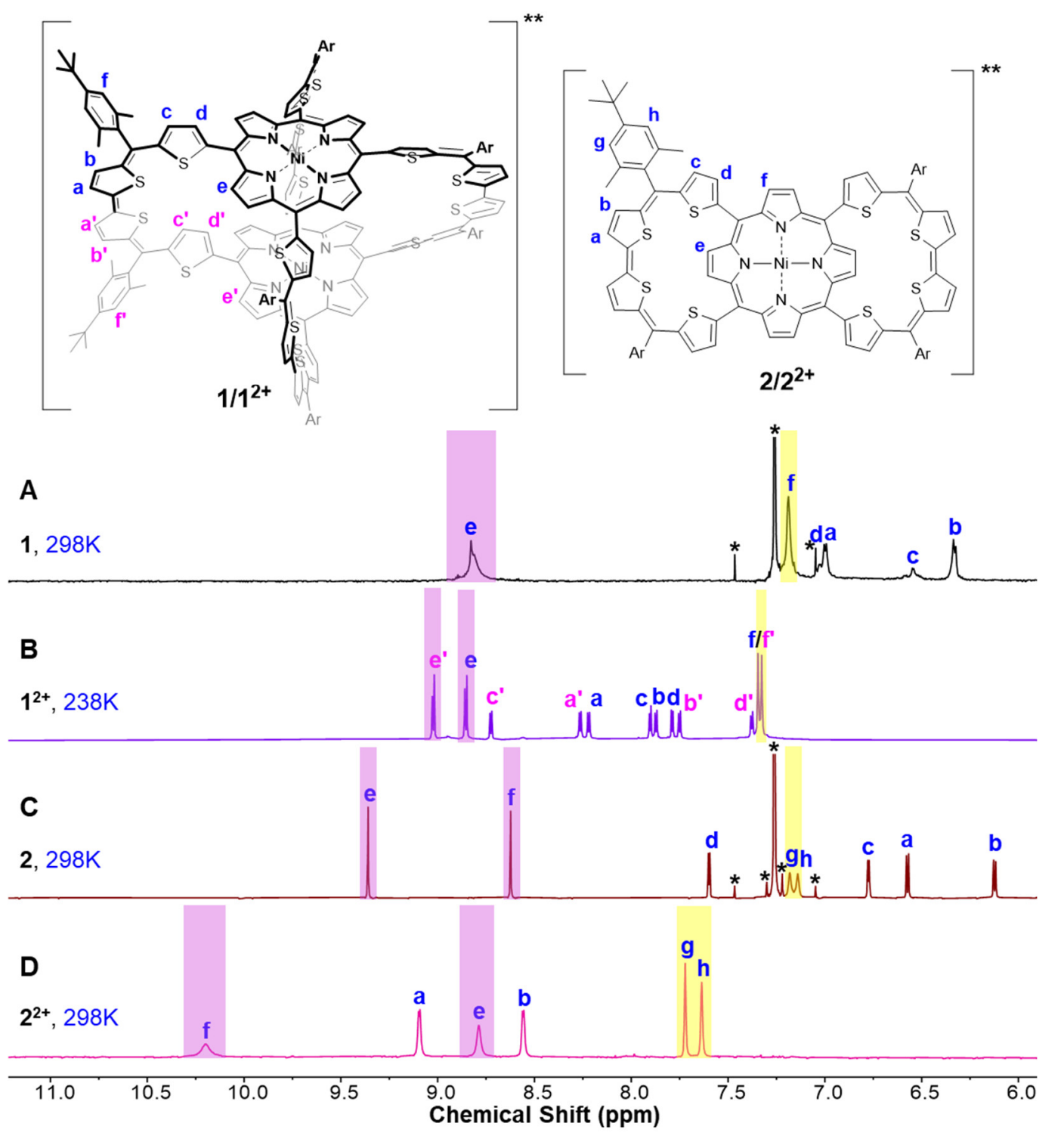

Figure 3. ${ }^{1} \mathrm{H}$ NMR spectra (500 MHz, aromatic region) of $1, \mathbf{1}^{\mathbf{2 +}}, \mathbf{2}$ and $\mathbf{2}^{\mathbf{2 +}}$. (A) $\mathbf{1}$ in $\mathrm{CDCl}_{3}$ at $298 \mathrm{~K}$. (B) $\mathbf{1}^{\mathbf{2 +}}$ in $\mathrm{CD}_{2} \mathrm{Cl}_{2}$ at $238 \mathrm{~K} . \mathbf{c}, 2$ in $\mathrm{CDCl}_{3}$ at $298 \mathrm{~K} . \mathbf{d}, \mathbf{2}^{\mathbf{2 +}}$ in $\mathrm{CD}_{2} \mathrm{Cl}_{2}$ at $298 \mathrm{~K}$. The top row are the chemical structures with labels (** is " 0 " for neutral compounds and " 2 " for the dications). The peaks labelled with * arise from the solvent $\mathrm{CHCl}_{3}$ and its satellite peaks. Peaks shaded by purple color represent the protons in porphyrin ring, while peaks shaded by yellow color represent the aromatic protons in the substituents.

The aromaticity of $\mathbf{1}$ was further investigated by the anisotropy of the induced current density (ACID),${ }^{55}$ nucleus-independent chemical shift (NICS), ${ }^{56}$ and 3D isochemical shielding surface (ICSS) ${ }^{57-58}$ calculations. The ACID plot reveals a clockwise diatropic ring current circuit in the porphyrin unit when the magnetic field is perpendicular to the porphyrin plane (along Y-axis) (Figure 4A), while the ACID plots with the magnetic field directed along $\mathrm{X}$ and $\mathrm{Z}$ axes do not show obvious ring current flow through the arms (Supplementary Information Fig. S12 and Fig. S13). The NICS iso $_{\text {at }}$ the geometric center is calculated to be 
$-4.0 \mathrm{ppm}$. The 3D ICSS map show a major magnetic shielding environment at above and below the porphyrin units (Figure 4B and Supplementary Information Fig. S28). All these calculations suggest that 1 only contains two localized aromatic porphyrin macrocycles and is not 3D globally aromatic, in consistent with experimental data.

A
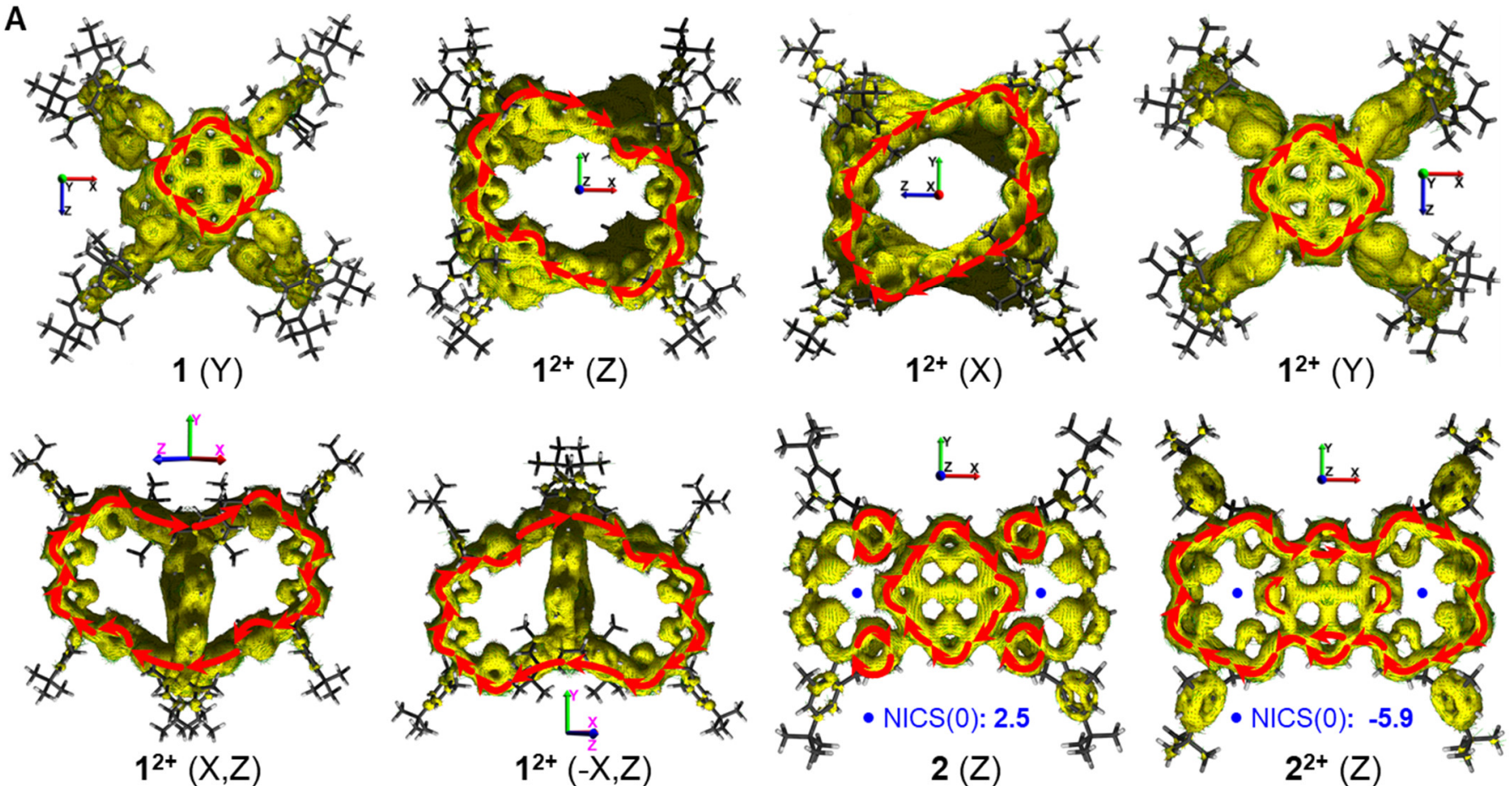

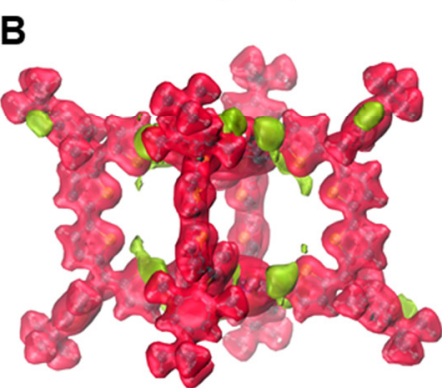

1 (ICSS)
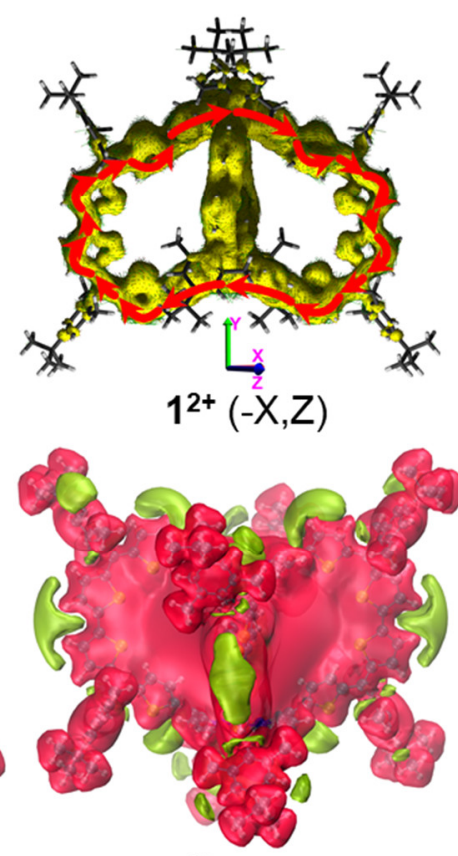

$1^{2+}($ ICSS $)$

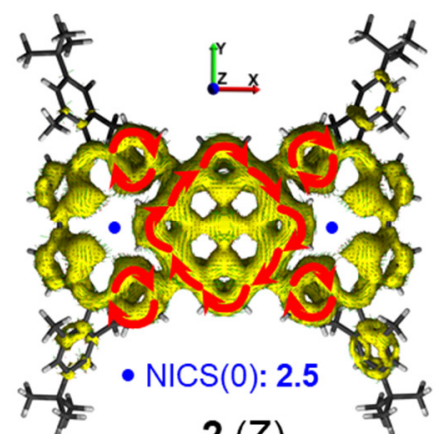

$2(Z)$

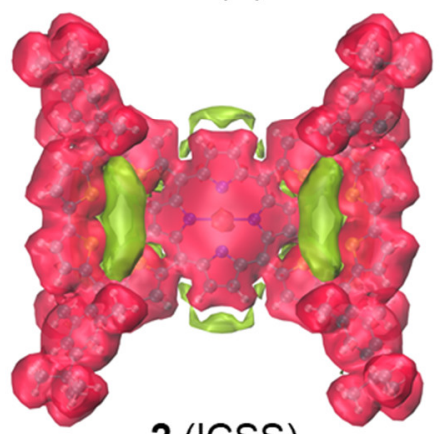

2 (ICSS)
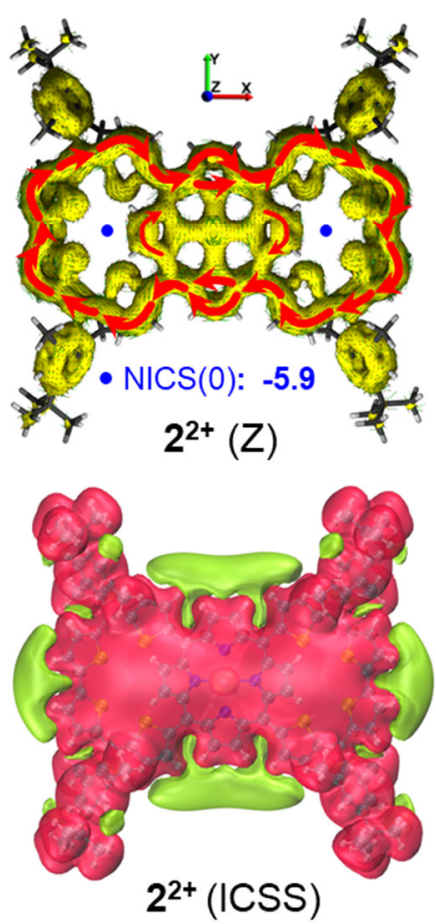

Figure 4. Theoretical calculations on the aromaticity of $1, \mathbf{1}^{2+}, \mathbf{2}$ and $2^{2+}$. (A) Calculated ACID plots with magnetic field along different axes in brackets (all vertically pointing out of the paper); $(\mathrm{X}, \mathrm{Z})$ represents the magnetic field along the middle of the positive $\mathrm{X}$ and $\mathrm{Z}$ axes, while $(-\mathrm{X}, \mathrm{Z})$ represents he magnetic field along the middle of negative $\mathrm{X}$ axis and positive $\mathrm{Z}$ axis; the red arrows indicate the diatropic current flow. (B) Calculated 3D ICSS maps (isovalue: 8.0 for $\mathbf{1}, 5.0$ for $\mathbf{1}^{\mathbf{2}}, 3.0$ for $\mathbf{2}$ and 2.0 for $\mathbf{2}^{\mathbf{2}}$ ); the red color represents NICS negative and the yellow color indicates area with positive NICS values. All calculations were performed based on the single-crystal structures. (See additional figures in Supplementary Information) 
The X-ray crystallographic structure of the dication $\mathbf{1}^{\mathbf{2 +}}$ measured at $100 \mathrm{~K}$ shows a dramatic change as compared to the neutral compound (Figure 2B). The molecule has a $C_{2}$ point of symmetry, with a $C_{2}$ rotational axis across the two $\mathrm{Ni}(\mathrm{II})$ centers. The four thiophene-based arms are labelled as $\alpha, \beta, \alpha^{\prime}$ and $\beta^{\prime}(\alpha$ is equivalent to $\alpha^{\prime}$ as $\beta$ is equivalent to $\beta^{\prime}$ ) to facilitate discussion. Both porphyrin units now adopt a saddleshaped conformation, with the four meso- carbons bent in an "up-down-up-down" mode relative to the mean plane. The two downward bent meso- carbons in one porphyrin unit are linked with the two downward bent meso- carbons in the other porphyrin unit through the arms $\alpha / \alpha^{\prime}$, while the other two upward bent mesocarbons connect with the two upward bent meso- carbons in the other porphyrin through the arms $\beta / \beta^{\prime}$. Overall, the molecule shows a highly distorted structure with two arms $\left(\alpha / \alpha^{\prime}\right)$ bent down and the other two $\left(\beta / \beta^{\prime}\right)$ bent up. Such conformation somewhat releases the strain and facilitates $\pi$-electron delocalization at three dimensions. While the quality of the crystallographic data does not allow a reliable bond length analysis, it is clear that the distortional angles between the porphyrins and the neighbouring thiophene units $\left(67.2^{\circ}\right.$, $44.9^{\circ}, 72.2^{\circ}$ and $44.2^{\circ}$ ) become smaller as compared to 1 , indicating more efficient $\pi$-orbital overlap. The two porphyrins units are more separated, with a mean distance of about $10.3 \AA$. At the meanwhile, the lateral diameter of the cavity (16.36 $\AA$ and $16.40 \AA$ ) defined by the same method to 1 becomes smaller.

Unlike the neutral compound $\mathbf{1}$, the ${ }^{1} \mathrm{H}$ NMR spectrum of $\mathbf{1}^{2+}$ in $\mathrm{CD}_{2} \mathrm{Cl}_{2}$ at $238 \mathrm{~K}$ displays two sets of well-resolved signals in accordance with two different halves separated by the middle points of the bithiophene units (Figure 3B and see Supplementary Information Fig. S6 and Fig. S7 for the assignment by 2D COSY and ROESY spectra). The resonances for all the protons on the $\pi$-conjugated backbone now appear in a low field $(\delta=7.37 \sim 9.03 \mathrm{ppm})$ with ten doublet peaks, and in particular the protons $a / a^{\prime}, b / b^{\prime}, c / c^{\prime}, d / d^{\prime}$ on the thiophene units are all considerably shifted downfield as compared to $\mathbf{1}$, indicating a global aromatic character. The different chemical shifts for the equivalent protons could be correlated to their different shielding/de-shielding chemical environment assuming that the whole cage is rigid and $3 \mathrm{D}$ aromatic in 
solution. The effective $\pi$-electron delocalization was also clearly shown in the calculated frontier molecular orbital profiles (Supplementary Information Fig. S34).

Calculations provide more insights to the aromaticity of $\mathbf{1}^{\mathbf{2}}$. Interestingly, ACID plots along five different axes $(\mathrm{Z}, \mathrm{X}, \mathrm{Y}, \mathrm{XZ}$ and $-\mathrm{XZ})$ all show a dominant clockwise ring current circuit cross the arms and the porphyrin units (Figure $4 \mathrm{~A})$. That means, this cage indeed is $3 \mathrm{D}$ globally aromatic. The NICS $(0)$ value in the geometric center is calculated to $-9.52 \mathrm{ppm}$, and NICS scan in the cavity along the $\mathrm{X}, \mathrm{Y}$ and $\mathrm{Z}$ axes reveal only negative NICS values (Supplementary Information Table 1), indicating an aromatic character. In addition, 3D ICSS map also demonstrate a more magnetically shielded cavity compared to that in $\mathbf{1}$ (Figure 4B and Supplementary Information Fig. S29), further supporting its 3D global aromaticity.

To understand this unique 3D aromatic system, the porphyrin units are dissected into four fragments labelled as $\mathrm{a} / \mathrm{b} / \mathrm{c} / \mathrm{d}$ for the top one and $\mathrm{a}^{\prime} / \mathrm{b}^{\prime} / \mathrm{c}^{\prime} / \mathrm{d}^{\prime}$ for the bottom one (Figure 5) corresponding to their X-ray structure with a $C_{2}$ symmetry (Figure $2 \mathrm{~B}$, top). Then, five types of $\pi$-conjugated macrocycles can be defined: (I) two equivalent macrocycles across $\alpha / \beta^{\prime}$ or $\alpha^{\prime} / \beta$ arms (i.e., a- $\alpha-a^{\prime}-\beta^{\prime}$ and $c-\alpha^{\prime}-c^{\prime}-\beta$ ); (II) two equivalent macrocycles across $\alpha / \beta$ or $\alpha^{\prime} / \beta^{\prime}$ arms (i.e., b- $\beta-b^{\prime}-\alpha$ and d- $\left.\beta^{\prime}-d^{\prime}-\alpha^{\prime}\right)$; (III) two equivalent porphyrin macrocycles (i.e., a-b-c-d and a'-b'-c'-d'); (IV) four equivalent macrocycles across $\alpha / \alpha^{\prime}$ arms (i.e., b-c- $\alpha^{\prime}-c^{\prime}-b^{\prime}-\alpha, b-c-\alpha^{\prime}-d^{\prime}-$ $a^{\prime}-\alpha, a-d-\alpha^{\prime}-d^{\prime}-a^{\prime}-\alpha$ and a-d- $\left.\alpha^{\prime}-c^{\prime}-b^{\prime}-\alpha\right)$; and (V) four equivalent macrocycles across $\beta / \beta^{\prime}$ arms (i.e., a-b- $\beta-b^{\prime}-a^{\prime}-$ $\beta^{\prime}$, a-b- $\beta-c^{\prime}-d^{\prime}-\beta$ ', c-d- $\beta^{\prime}-d^{\prime}-c^{\prime}-\beta$ and $c-d-\beta^{\prime}-a^{\prime}-b$ '- $\left.\beta\right)$. Notably, all these five types of macrocycles are aromatic according to the ACID calculations, and one can also draw an [n] annulene-like conjugation pathway with 46, 46, 18, 54, 54 delocalized $\pi$-electrons, respectively (Supplementary Information Fig. S24 and Fig. S25). These 2D canonical forms resonate between each other and form a highly stable 3D aromatic system containing five types of 2D Hückel aromatic macrocycles. The positive charges are also delocalized at three dimensions (Supplementary Information Fig. S32). On the other hand, the $\pi$-conjugated skeleton of $\mathbf{1}^{\mathbf{2 +}}$ has total 114 delocalized $\pi$ electrons (excluding the sulfur atoms which contribute little to the ring current 
according to ACID plots) and a much lower symmetry as compared to the $I_{\mathrm{h}}$ symmetric fullerenes, and thus it is clear that it does not follow Hirsch's $2(\mathrm{~N}+1)^{2}$ spherical aromaticity rule. In our previous studies on the $D_{3}$ symmetric, 3D globally aromatic cage $\boldsymbol{c}-\mathbf{T}_{12}{ }^{6+},{ }^{17}$ all the three macrocycles across the two bridge head carbons and any two of the three arms are actually also 2D Hückel aromatic. Therefore, it seems that to attain 3D global aromaticity in molecular cage, all the formally available $2 \mathrm{D} \pi$-conjugated macrocycles should be aromatic.

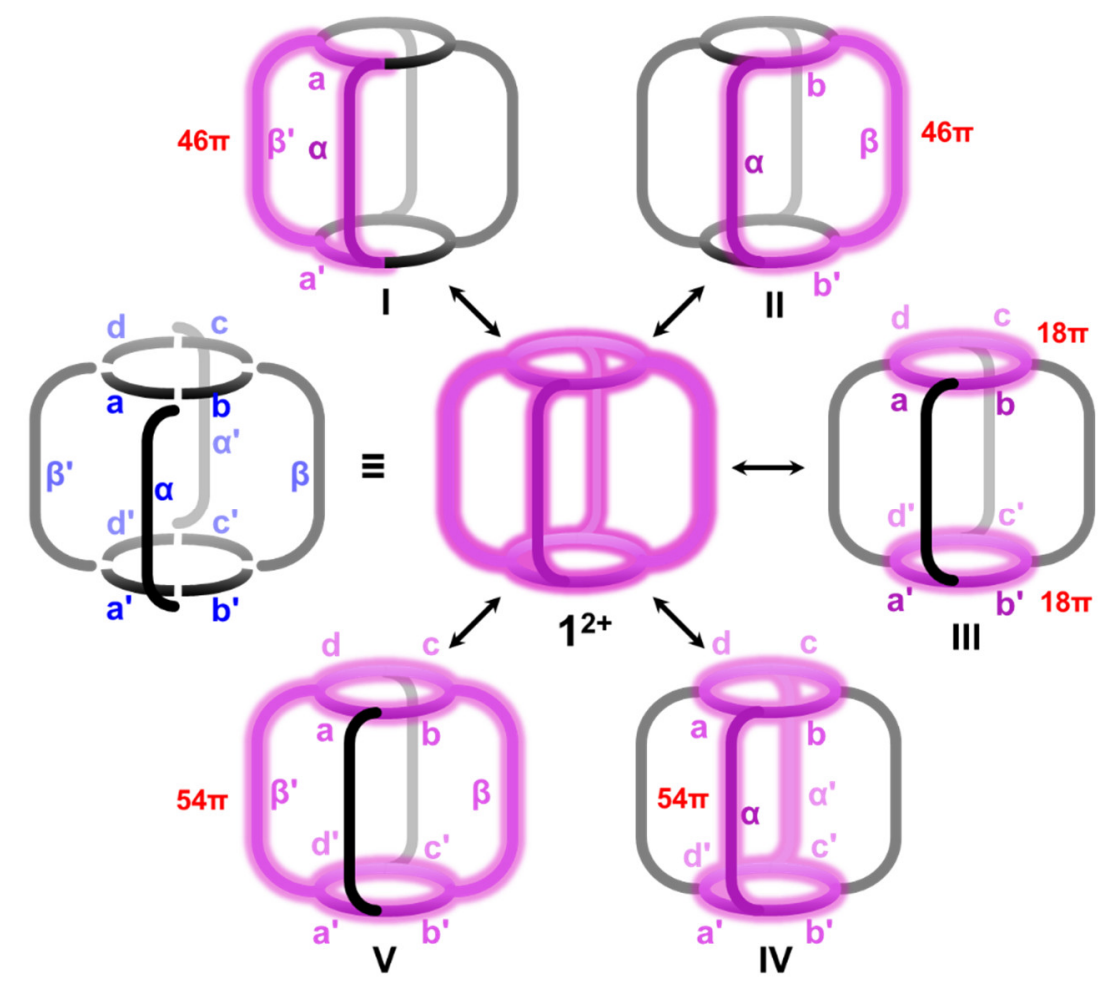

Figure 5. Schematic presentation of the 3D global aromaticity of $\mathbf{1}^{2+}$. The $\pi$-conjugated skeleton was decomposed into 12 fragments according to its X-ray structure and labelled by a, a', b, b', c, c', d, d', $\alpha, \alpha^{\prime}, \beta$, $\beta^{\prime}$ (the left cage in black/grey color). The 3D aromaticity can be explained by the 2D Hückel aromaticity in five types of macrocycles formed from different fragments, which are highlighted in purple color.

The switch from porphyrin-based localized aromaticity to global aromaticity along the whole tricyclic system upon chemical oxidation was also observed in the model compound 2. X-ray crystallographic structure of $\mathbf{2}$ shows a slightly distorted saddle-shaped porphyrin core, and the two fused earring-like units are bent toward the same side relative to the porphyrin mean plane, with a cavity depth about $2.0 \AA$ (Figure 2C). The distortional angles between the porphyrins and the neighboured thiophene units are $53.4^{\circ}, 58.8^{\circ}$, 
$66.8^{\circ}$ and $67.2^{\circ}$, respectively. Upon oxidation to the dication, the two arms are further bent with a deeper cavity (depth: $\sim 3.3 \AA$ ), but the distortional angles between the porphyrin and the arms become smaller $\left(29.2^{\circ}\right.$, $33.3^{\circ}, 43.7^{\circ}$ and $52.4^{\circ}$ ), implying a better $\pi$-conjugation (Figure 2D). ACID plot of 2 shows a diatropic ring current circuit in the central porphyrin unit and the four thiophene rings directly linked to the porphyrin unit, while the bithiophene units are non-aromatic, similar to 1. The NICS value at the center of the two earrings in 2 is calculated to be $2.5 \mathrm{ppm}$, which should be arisen from the de-shielding effect from the nearby aromatic porphyrin and thiophene rings. The 3D ICSS map also shows a dominant shielding environment above and below the porphyrin unit (Figure 4B). On the other hand, the calculated ACID plot of the $\mathbf{2}^{2+}$ displays a dominant clockwise current circuit through the outer periphery of the $\pi$-conjugated skeleton (Figure $4 \mathrm{~A}$ ). However, detailed analysis of the chemical structure suggest that this is actually due to a superposition effect the ring currents from three aromatic rings including two aromatic earrings and one aromatic porphyrin unit, which possess a [22] and [18]annulene-like conjugation pathway, respectively (Supplementary Information Fig. S26). The cancelation of the clockwise ring current flow at the bridges (herein, the two fragments on porphyrin shared with the two earrings) leads to weak clockwise ring current at the porphyrin unit and an overall high diatropic current density along the outer periphery, which is similar to the tricyclic anthracene molecule. The calculated NICS value at the two earring centers now becomes $-5.9 \mathrm{ppm}$, indicating a switch from non-aromaticity to aromaticity. The calculated 3D ICSS map of $\mathbf{2}^{2+}$ further supports a magnetic shielding environment for all three cycles (Figure 4B). Therefore, the dication $\mathbf{2}^{2+}$ is also globally aromatic, with all three possible $\pi$-conjugated macrocycles being 2D Hückel aromatic.

The change of electronic structure and aromaticity from $\mathbf{2}$ to $2^{2+}$ was also demonstrated by experiment. The ${ }^{1} \mathrm{H}$ NMR spectrum of 2 in $\mathrm{CDCl}_{3}$ at $298 \mathrm{~K}$ (Figure 3C) reveals a typical aromatic porphyrin structure, with resonances for the $\beta$-H appearing at the low field ( $\delta=9.36$ and $8.62 \mathrm{ppm}$ for protons $e$ and $f$, respectively). The four thiophenes directly linked with the porphyrin units are also aromatic $(\delta=6.78$ and $7.60 \mathrm{ppm}$ for 
protons $c$ and $d$, respectively), while the quinoidal bithiophene units are non-aromatic $(\delta=6.57$ and 6.12 ppm for protons $a$ and $b$, respectively). The peaks for the aromatic protons $g$ and $h$ on the aryl substituents are split $(\delta=7.18,7.14 \mathrm{ppm})$, indicating that the rotation of the aryl substituents is slow on NMR scale in this rigid tricyclic molecule. The ${ }^{1} \mathrm{H}$ NMR spectrum of $\mathbf{2}^{2+}$ in $\mathrm{CD}_{2} \mathrm{Cl}_{2}$ at $298 \mathrm{~K}$ shows that the resonances for the protons $f$ on the porphyrin unit $(\delta=10.20 \mathrm{ppm})$, protons $a(\delta=9.10 \mathrm{ppm})$ and $b(\delta=8.55 \mathrm{ppm})$ on the bithiophene units, and the protons $g$ and $h$ on the aryl substituents $(\delta=7.72,7.63 \mathrm{ppm})$ are all shifted to lower field as compared with that in $\mathbf{2}$, which can be explained by the de-shielding effect from the diatropic ring current along the outer periphery. However, the proton $e$ on the porphyrin unit above the two earrings is shifted to higher field $(\delta=8.79 \mathrm{ppm})$ due to the shielding effect from the diatropic ring current. Nevertheless, the chemical shift indicates an overall de-shielding chemical environment which can be explained by three reasons: (a) the central porphyrin unit is still aromatic; (b) the backbone is non-planar and the proton $e$ is far from the geometric center of the earrings (Figure 2D); and (c) the two positive charges are delocalized (Supplementary Information Fig. S32), which result in decreased electron density. It is also noted that the resonances for the protons $c$ and $d$ coalesced at room temperature, which is likely due to restricted rotation as we previously observed in a similar system. ${ }^{54}$ In accordance with the global aromatic character, the compound $\mathbf{2}^{2+}$ in DCM shows an intense band with $\lambda_{\text {abs }}$ at about $1068 \mathrm{~nm}$.

\section{Conclusion}

In summary, a complex porphyrin and thiophene-based fully $\pi$-conjugated molecular cage (1) was synthesized by a facile strategy. A switch from 2D local aromaticity to 3D global aromaticity upon twoelectron oxidation was demonstrated in its dication $\left(\mathbf{1}^{\mathbf{2}}\right)$. Importantly, we found that all the five types of $\pi$ conjugated 2D macrocycles formed from the constructional fragments are Hückel aromatic. This study, together with our previous analysis on a $D_{3}$ symmetric cage $\boldsymbol{c}-\mathbf{T}_{\mathbf{1 2}}{ }^{\mathbf{6}}$, strongly suggests that the $3 \mathrm{D}$ global aromaticity actually can be explained by the 2D Hückel aromaticity of the individual $\pi$-conjugated 
macrocycles that can be drawn in the $3 \mathrm{D} \pi$-conjugated skeleton. Such scenario is also observed in the tricyclic model compound 2. All these studies again demonstrate a fundamental chemical principle, that is, the $\pi$ conjugated molecules always have tendency to become aromatic with the lowest energy state. The current $C_{2}$ symmetric cage $\mathbf{1}^{\mathbf{2}}$ obviously does not follow Hirsch's $2(\mathrm{~N}+1)^{2}$ spherical aromaticity rule. Continuous searching for highly symmetric, $\pi$-conjugated molecular cages is still needed to answer the question.

\section{Experimental procedures}

The full experimental details, characterization data, and theoretical calculation results can be found in the Supplementary Information.

\section{Data availability}

Crystallographic data for the structures reported in this Article have been deposited at the Cambridge Crystallographic Data Centre, under deposition numbers CCDC 2080995 (1), $2080996\left(\mathbf{1}^{\mathbf{2 +}}\right), 2080997$ (2), and $2080998\left(\mathbf{2}^{2+}\right)$.

\section{Acknowledgment}

J. W. acknowledges financial support from the NRF Investigatorship (NRF-NRFI05-2019-0005) and MOE Tier 2 project (MOE2018-T2-2-094).

\section{Author contributions}

J.W. and L.R. conceived the project; L.R. synthesized the compounds, collected the experimental data and did partial calculations; Y.H. conducted partial theoretical calculations; Y.H. and X.H. did the X-ray analysis. All authors participated in the manuscript writing.

\section{Competing interests}

The authors declare no competing interests.

\section{References}

1. Hückel, E. (1931). Quantentheoretische beiträge zum benzolproblem. Z. Phys. 70, 204-286. 
2. Breslow, R. (1973). Antiaromaticity. Acc. Chem. Res. 6, 393-398.

3. Krygowski, T. M., Cyrañski, M. K., Czarnocki, Z., Häfelinger, G., and Katritzky, A. R. (2000). Aromaticity: a theoretical concept of immense practical importance. Tetrahedron 56, 1783-1796.

4. Sondheimer, F. (2002). Annulenes. Acc. Chem. Res. 5, 81-91.

5. Cyranski, M. K. (2005). Energetic aspects of cyclic pi-electron delocalization: evaluation of the methods of estimating aromatic stabilization energies. Chem. Rev. 105, 3773-3811.

6. Stępień, M., and Latos-Grażyński, L. (2008). Aromaticity and tautomerism in porphyrins and porphyrinoids. Top. Heterocycl. Chem. 19, 82-153.

7. Saito, S., and Osuka, A. (2011). Expanded porphyrins: intriguing structures, electronic properties, and reactivities. Angew. Chem. Int. Ed. 50, 4342-4373.

8. Tanaka, T., and Osuka, A. (2017). Chemistry of meso-aryl-substituted expanded porphyrins: aromaticity and molecular twist. Chem. Rev. 117, 2584-2640.

9. Peeks, M. D., Claridge, T. D. W., and Anderson, H. L. (2017). Aromatic and antiaromatic ring currents in a molecular nanoring. Nature 541, 200-203.

10. Rickhaus, M., Jirasek, M., Tejerina, L., Gotfredsen, H., Peeks, M. D., Haver, R., Jiang, H.-W., Claridge, T. D. W., and Anderson, H. L. (2020). Global aromaticity at the nanoscale. Nat. Chem. 12, 236-241.

11. Liu, C., Sandoval-Salinas, M. E., Hong, Y., Gopalakrishna, T. Y., Phan, H., Aratani, N., Herng, T. S., Ding, J., Yamada, H., Kim, D., Casanova, D., and Wu, J. (2018). Macrocyclic polyradicaloids with unusual super-ring structure and global aromaticity. Chem 4, 1586-1595.

12. Liu, C., Ni, Y., Lu, X., Li, G., and Wu, J. (2019). Global aromaticity in macrocyclic polyradicaloids: Hückel's rule or Baird's rule?. Acc. Chem. Res. 52, 2309-2321.

13. Heilbronner, E. (1964). Hückel molecular orbitals of Möbius-type conformations of annulenes. Tetrahedron Lett. 29, 1923-1928. 
14. Ajami, D., Oeckler, O., Simon, A., and Herges, R. (2003). Synthesis of a Möbius aromatic hydrocarbon. Nature 426, 819-821.

15. Stępień, M., Latos-Grażyński, L., Sprutta, N., Chwalisz, P., and Szterenberg, L. (2007). Expanded porphyrin with a split personality: a Hückel-Möbius aromaticity switch. Angew. Chem. Int. Ed. 46, 78697873.

16. Tanaka, Y., Saito, S., Mori, S., Aratani N., Shinokubo, H., Shibata, N., Higuchi, Y., Yoon, Z. S., Kim, K. S., Noh, S. B., Park, J. K., Kim, D., and Osuka, A. (2008). Metalation of expanded porphyrins: a chemical trigger used to produce molecular twisting and Möbius aromaticity. Angew. Chem. Int. Ed. 47, 681-684.

17. Yoon, Z. S., Osuka, A., and Kim, D. (2009). Möbius aromaticity and antiaromaticity in expanded porphyrins. Nat. Chem. 1, 113-122.

18. Stępień, M., Sprutta, N., and Latos-Grażyński, L. (2011). Fig. Seights, Möbius bands, and more: conformation and aromaticity of porphyrinoids. Angew. Chem. Int. Ed. 50, 4288-4340.

19. Craig, D. P., and Paddock, N. L. (1958). A Novel type of aromaticity. Nature 181, 1052-1053.

20. Zhu, C. Q., and Xia, H. P. (2018). Carbolong chemistry: A story of carbon chain ligands and transition metals. Acc. Chem. Res. 51, 1691-1700.

21. Baird, N. C. (2002). Quantum organic photochemistry. II. Resonance and aromaticity in the lowest ${ }^{3} \pi \pi^{*}$ state of cyclic hydrocarbons. J. Am. Chem. Soc. 94, 4941-4948.

22. Wörner, H. J., and Merkt, F. (2006). Photoelectron spectroscopic study of the first singlet and triplet states of the cyclopentadienyl cation. Angew. Chem. Int. Ed. 45, 293-296.

23. Ottosson, H. (2012). Organic photochemistry: Exciting excited-state aromaticity. Nat. Chem. 4, 969-971.

24. Rosenberg, M., Dahlstrand, C., Kilså, K., and Ottosson, H. (2014). Excited state aromaticity and antiaromaticity: opportunities for photophysical and photochemical rationalizations. Chem. Rev. 114, $5379-5425$. 
25. Sung, Y. M., Yoon, M.-C., Lim, J. M., Rath, H., Naoda, K., Osuka A., and Kim, D. (2015). Reversal of Hückel (anti)aromaticity in the lowest triplet states of hexaphyrins and spectroscopic evidence for Baird's rule. Nat. Chem. 7, 418-422.

26. Lipscomb, W. N. (1959). Probable structure of the $\mathrm{B}_{10} \mathrm{H}_{10}{ }^{2-}$ ion. J. Am. Chem. Soc. 81, 5833-5834.

27. Schleyer, P. v. R., Subramanian, G., and Dransfeld, A. (1996). Decisive evidence for nonclassical bonding in five-vertex closo-Boranes, $\mathrm{X}_{2} \mathrm{~B}_{3} \mathrm{H}_{3}, \mathrm{X}=\mathrm{N}, \mathrm{CH}, \mathrm{P}, \mathrm{SiH}, \mathrm{BH}^{-}$. J. Am. Chem. Soc. 118, 9988-9989.

28. King, R. B. (2001). Three-dimensional aromaticity in polyhedral boranes and related molecules. Chem. Rev. 101, 1119-1152.

29. Huang, W., Sergeeva, P. A., Zhai, H.-J., Averkiev, B. B., Wang L.-S., and Boldyrev, A. I. (2010). A concentric planar doubly $\pi$-aromatic $\mathrm{B}_{19^{2-}}$ cluster. Nat. Chem. 2, 202-206.

30. Sergeeva, A. P., Popov, I. A., Piazza, Z. A., Li, W.-L., Romanescu, C., Wang, L.-S., and Boldyrev, A. I. (2014). Understanding boron through size-selected clusters: Structure, chemical bonding, and fluxionality. Acc. Chem. Res. 47, 1349-1358.

31. Zhai, H.-J., Zhao, Y.-F., Li, W.-L., Chen, Q., Bai, H., Hu, H.-S., Piazza, Z. A., Tian, W.-J., Lu, H.-G., Wu, Y.-B., Mu, Y.-W., Wei, G.-F., Liu, Z.-P., Li, J., Li, S.-D., and Wang, L.-S. (2014). Observation of an all-boron fullerene. Nat. Chem. 6, 727-731.

32. Poater, J., Solà, M., Viñas, C., and Teixidor, F. (2014). $\pi$-Aromaticity and three-dimensional aromaticity: Two sides of the same coin? Angew. Chem. Int. Ed. 53, 12191-12195.

33. Hirsch, A., Chen, Z., and Jiao, H. (2000). Spherical aromaticity in $I_{\mathrm{h}}$ symmetrical fullerenes: The $2(\mathrm{~N}+1)^{2}$ rule. Angew. Chem. Int. Ed. 39, 3915-3917.

34. Bühl, M., and Hirsch, A. (2001). Spherical aromaticity of fullerenes. Chem. Rev. 101, 1153-1183.

35. Reiher, M., and Hirsch, A. (2003). From rare gas atoms to fullerenes: Spherical aromaticity studied from the point of view of atomic structure theory. Chem. Eur. J. 9, 5442-5452. 
36. Chen, Z., and King, R. B. (2005). Spherical aromaticity: recent work on fullerenes, polyhedral boranes, and related structures. Chem. Rev. 105, 3613-3642.

37. Bremer, M., Schleyer, P. v. R., Schötz, K., Kausch, M., and Schindler, M. (1987). Four-center twoelectron bonding in a tetrahedral topology. Experimental realization of three-dimensional homoaromaticity in the 1,3-dehydro-5,7-adamantanediyl dication. Angew. Chem. Int. Ed. Engl. 26, 761763.

38. Chen, Z., Jiao, H., Hirsch, A., and Schleyer, P. v. R. (2002). Spherical homoaromaticity. Angew. Chem. Int. Ed. 41, 4309-4312.

39. Johansson, M. P., Sundholm, D., and Vaara, J. (2004). Au32: A 24-carat golden fullerene. Angew. Chem. Int. Ed. 43, 2678-2681.

40. Wang, J., Jellinek, J., Zhao, J., Chen, Z., King, R. B., and Schleyer, P. v. R. (2005). Hollow cages versus space-filling structures for medium-sized gold clusters: The spherical aromaticity of the $\mathrm{Au}_{50} \mathrm{Cage}$. J. Phys. Chem. A 109, 9265-9269.

41. Poater J., and Solà, M. (2011). Open-shell spherical aromaticity: the $2 N^{2}+2 N+1$ (with $S=N+1 / 2$ ) rule. Chem. Commun. 47, 11647-11649.

42. Corminboeuf, C., Schleyer, P. v. R., and Warner, P. (2007). Are antiaromatic rings stacked face-to-face aromatic? Org. Lett. 9, 3263-3266.

43. Nozawa, R., Tanaka, H., Cha, W.-Y., Hong, Y., Hisaki, I., Shimizu, S., Shin, J.-Y., Kowalczyk, T., Irle, S., Kim D., and Shinokubo, H. (2016). Stacked antiaromatic porphyrins. Nat. Commun. 7, 13620.

44. Nozawa, R., Kim, J., Oh, J., Lamping, A., Wang, Y., Shimizu, S., Hisaki, I., Kowalczyk, T., Fliegl, H., Kim, D., and Shinokubo, H. (2019). Three-dimensional aromaticity in an antiaromatic cyclophane. Nat. Commun. 10, 3576 .

45. Högberg, H.-E., Thulin, B., and Wennerström, O. (1977). Bicyclophanehexaene, a new case cyclophane 
from a sixfold wittig reaction. Tetrahedron Lett. 18, 931-934.

46. Wu, Z., Lee, S., and Moore, J. S. (1992). Synthesis of three-dimensional nanoscaffolding. J. Am. Chem. Soc. $114,8730-8732$.

47. Kayahara, E., Iwamoto, T., Takaya, H., Suzuki, T., Fujitsuka, M., Majima, T., Yasuda, N., Matsuyama, N., Seki S., and Yamago, S. (2013). Synthesis and physical properties of a ball-like three-dimensional $\pi$ conjugated molecule. Nat. Commun. 4, 2694.

48. Matsui, K., Segawa, Y., and Itami, K. (2014). All-benzene carbon nanocages: size-selective synthesis, photophysical properties, and crystal structure. J. Am. Chem. Soc. 136, 16452-16458.

49. Song, J., Aratani, N., Shinokubo, H., and Osuka, A. (2010). A porphyrin nanobarrel that encapsulates $\mathrm{C}_{60}$. J. Am. Chem. Soc. 132, 16356-16357.

50. Zhang, C., Wang, Q., Long, H., and Zhang, W. (2011). A highly $\mathrm{C}_{70}$ selective shape-persistent rectangular prism constructed through one-step alkyne metathesis. J. Am. Chem. Soc. 133, 20995-21001.

51. Ke, X.-S., Kim, T., He, Q., Lynch, V. M., Kim, D., and Sessler, J. L. (2018). Three-dimensional fully conjugated carbaporphyrin cage. J. Am. Chem. Soc. 140, 16455-16459.

52. Cha, W.-Y., Kim, T., Ghosh, A., Zhang, Z., Ke, X.-S., Ali, R., Lynch, V. M., Jung, J., Kim, W., Lee, S., Fukuzumi, S., Park, J. S., Sessler, J. L., Chandrashekar T. K., and Kim, D. (2017). Bicyclic Baird-type aromaticity. Nat. Chem. 9, 1243-1248.

53. Ni, Y., Gopalakrishna, T. Y., Phan, H., Kim, T., Herng, T. S., Han, Y., Tao, T., Ding, J., Kim, D., and Wu, J. (2020). 3D global aromaticity in a fully conjugated diradicaloid cage at different oxidation states. Nat. Chem. 12, 242-248.

54. Ren, L., Gopalakrishna, T. Y., Park, I. H., Han, Y., and Wu, J. (2020). Porphyrin/quinoidal-bithiophenebased macrocycles and their dications: Template-free synthesis and global aromaticity. Angew. Chem. Int. Ed. 59, 2230-2234. 
55. Geuenich, D., Hess, K., Kohler, F., and Herges, R. (2005). Anisotropy of the induced current density (ACID), a general method to quantify and visualize electronic delocalization. Chem. Rev. 105, 37583772.

56. Schleyer, P. v. R., Maerker, C., Dransfeld, A., Jiao, H., and van Eikema Hommes, N. J. R. (1996). Nucleus-independent vhemical shifts: a simple and efficient aromaticity probe. J. Am. Chem. Soc. 118, $6317-6318$.

57. Humphrey, W., Dalke, A., and Schulten, K. (1996). VMD: Visual molecular dynamics. J. Mol. Graph. 14, $33-38$.

58. Lu, T., and Chen, F. (2012). Multiwfn: a multifunctional wavefunction analyzer. J. Comput. Chem. 33, $580-592$. 